Pacific Journal of Mathematics

RELATIONS BETWEEN CONVERGENCE OF SERIES AND 


\title{
RELATIONS BETWEEN CONVERGENCE OF SERIES AND CONVERGENCE OF SEQUENCES
}

\author{
D. LANDERS AND L. RogGE
}

Let $A=\left(a_{n}\right)_{n \in \mathrm{N}}$ be a sequence of real numbers. For $\xi \in$ $(0,1)$ define

$$
S_{n}(\xi, A):=\sum_{k=[n \xi]+1}^{n} a_{k}, \quad n \in \mathbf{N}
$$

where $[x]$ is the greatest integer less than or equal to $x$. If no ambiguity can arise we write $S_{n}(\xi)$ instead of $S_{n}(\xi, A)$. In the theory of regularly varying sequences the problem arose of concluding from the convergence of the sequence $S_{n}(\xi), n \in \mathbf{N}$, for all $\xi$ in an appropriate set $K \subset(0,1)$ of real numbers, that the sequence $a_{n}, n \in \mathbf{N}$, converges to zero. In this paper we give some positive results for the case that $K$ consists of two elements.

In [3] it was shown that such a conclusion is not possible if $K$ consists only of a single rational number and that the conclusion is possible if $K=\{\xi, 1-\xi\}$ with $\xi \in(0,1)$ irrational. The question whether such a conclusion is possible if $K$ consists of one irrational or all rational numbers was answered negatively in [4].

DEFINITION 1. If $a_{n} \in\{0,1\}, n \in \mathbf{N}$, and $a_{n}=1$ for infinitely many $n \in \mathbf{N}$, then we call $A:=\left(a_{n}\right)_{n \in \mathbf{N}}$ a $0-1$ sequence.

Let $A=\left(a_{n}\right)_{n \in \mathrm{N}}$ be a sequence of real numbers such that $S_{n}\left(\xi_{1}, A\right)$, $n \in \mathbf{N}$, and $S_{n}\left(\xi_{2}, A\right), n \in \mathbf{N}$, are convergent for different $\xi_{1}, \xi_{2} \in(0,1)$. Let $\alpha=\liminf _{n \in \mathrm{N}} a_{n}$ and $\beta=\limsup _{n \in \mathrm{N}} a_{n}$. Since $\alpha=\beta$ implies $\lim _{n \in \mathrm{N}} a_{n}=0-$ as otherwise $\lim _{n \in \mathrm{N}}\left|S_{n}\left(\xi_{1}, A\right)\right|=\propto$ - the Lemma below shows that only the following three cases are possible:

(I) $\quad \lim _{n \in \mathrm{N}} a_{n}=0$

(II) $\alpha<\beta$ and each $\gamma \in(\alpha, \beta)$ is an accumulation point of $a_{n}$, $n \in \mathbf{N}$

(III) $\alpha<\beta$ and there exists a $0-1$ sequence $B$ such that $S_{n}\left(\xi_{i}, B\right)$, $n \in \mathbf{N}$ converges for $i=1,2$.

LEMMA 2. Let $A=\left(a_{n}\right)_{n \in \mathrm{N}}$ be a sequence of real numbers such that not every point between $\alpha:=\liminf _{n \in \mathrm{N}} a_{n}$ and $\beta:=\limsup _{n \in \mathrm{N}} a_{n}$ is an accumulation point of the sequence $a_{n}, n \in \mathbf{N}$. If $\xi_{1} \in(0,1), i=1, \cdots, k$, and $S_{n}\left(\xi_{1}, A\right), n \in \mathbf{N}$, is convergent for $i=1, \cdots, k$, then there exists a $0-1$ sequence $B=\left(b_{n}\right)_{n \in \mathrm{N}}$, such that $S_{n}\left(\xi_{1}, B\right), n \in \mathbf{N}$, is convergent for $i=$ $1, \cdots, k$. 
Proof. Since not every point between $\alpha$ and $\beta$ is an accumulation point of the sequence $a_{n}, n \in \mathbf{N}$, there exist $\gamma, \delta$ with $\alpha<\gamma<\delta<\beta$ such that $a_{n} \notin(\gamma, \delta)$ for all $n \in \mathbf{N}$. Since we can consider the sequence $\left(a_{n}\right)_{n \in \mathbf{N}}$ or the sequence $\left(-a_{n}\right)_{n \in \mathrm{N}}$, we may w.l.g. assume that $\gamma \geqq 0$.

Let $b_{n}=0$ if $a_{n} \leqq \gamma$ and $b_{n}=1$ if $a_{n} \geqq \delta$. Then $B=\left(b_{n}\right)_{n \in \mathrm{N}}$ is a $0-1$ sequence. According to our assumption there exists $n_{0} \in \mathbf{N}$ such that

$$
\left|S_{n+1}\left(\xi_{i}, A\right)-S_{n}\left(\xi_{i}, A\right)\right|<\delta-\gamma \quad \text { if } \quad n \geqq n_{0}, \quad i=1, \cdots, k .
$$

Since

$$
S_{n+1}\left(\xi_{i}, A\right)-S_{n}\left(\xi_{i}, A\right)=\left\{\begin{array}{l}
a_{n+1}, \quad \text { if }\left[n \xi_{i}\right]=\left[(n+1) \xi_{i}\right] \\
a_{n+1}-a_{\left[n \xi_{i]}+1\right.}, \quad \text { otherwise }
\end{array}\right.
$$

we obtain from $(+)$ that $S_{n+1}\left(\xi_{i}, B\right)=S_{n}\left(\xi_{i}, B\right)$ for all $n \geqq n_{0}, i=1, \cdots, k$, whence $S_{n}\left(\xi_{i}, B\right), n \in \mathbf{N}$, converges for $i=1, \cdots, k$.

Now we shall prove that for most pairs of real numbers - more exactly for all $\xi_{1}, \xi_{2} \in(0,1)$ with $\xi_{1}^{r} \neq \xi_{2}^{s}$ for all $r, s \in \mathbf{N}$ - case (III) cannot occur.

THEOREM 3. Let $a_{n}, n \in \mathbf{N}$, be a sequence of real numbers and $\xi_{1}, \xi_{2} \in(0,1)$ such that $S_{n}\left(\xi_{i}\right), n \in \mathbf{N}$, is convergent for $i=1,2$.

Assume that:

$$
\xi_{1}^{r} \neq \xi_{2}^{s} \text { for all } \quad r, s \in \mathbf{N} \text {. }
$$

Then $a_{n}, n \in \mathbf{N}$, converges to zero or every real number between $\liminf _{n \in \mathrm{N}} a_{n}$ and $\lim \sup _{n \in \mathrm{N}} a_{n}$ is an accumulation point of $a_{n}, n \in \mathbf{N}$.

Proof. Assume that the assertion is false.

Hence according to Lemma 2 we may assume that $a_{n}, n \in \mathbf{N}$, is a $0-1$ sequence. Let $\xi_{1}<\xi_{2}$ and put $\eta_{i}:=1 / \xi_{\text {i }}$.

Then there exists $z>1$ with $\eta_{1}=\eta_{2}^{z}$. We have to prove that $z$ is rational. Since $S_{n}\left(\xi_{i}\right), n \in \mathbf{N}$, converges for $i=1,2$ and $a_{n}, n \in \mathbf{N}$, is a $0-1$ sequence, there exists $n_{0} \in \mathbf{N}$ with

$$
\begin{aligned}
& S_{n}\left(\xi_{i}\right)=S_{n_{0}}\left(\xi_{i}\right) \quad \text { for } \quad n \geqq n_{0} \quad(i=1,2) \\
& n_{0}\left(1-\eta_{2}^{-1 / 3 j}\right)>2 /\left(\eta_{2}-1\right)
\end{aligned}
$$

where $j:=\lim _{n \in \mathbf{N}} S_{n}\left(\xi_{2}\right) \in \mathbf{N}$.

Let $N_{1}:=\left\{n \in \mathbf{N}: n>n_{0}\right.$ and $\left.a_{n}=1\right\}$ and let $\langle a\rangle:=\min \{n \in \mathbf{N}: a \leqq$ $n\}$ for $n \geqq 1$. 
Since $\langle t \cdot \eta\rangle=\inf \{n \in \mathbf{N}:[n \cdot 1 / \eta]=t\}, t \in \mathbf{N}, \eta>1$, we have

$$
S_{\langle t \cdot \eta\rangle}\left(\frac{1}{\eta}\right)-S_{\langle t \cdot \eta\rangle-1}\left(\frac{1}{\eta}\right)=a_{\langle t \cdot \eta\rangle}-a_{t} \quad(t \in \mathbf{N}, \eta>1)
$$

and hence we obtain from (1) that

$$
t \in \mathbf{N}_{1} \text { implies }\left\langle t \cdot \eta_{i}\right\rangle \in \mathbf{N}_{1} \text { for } i=1,2 \text {. }
$$

Define inductively for $t \in \mathbf{N}_{1}, \eta>1$

$$
\tau^{0}(t, \eta):=t
$$

and

$$
\tau^{n}(t, \eta):=\left\langle\tau^{n-1}(t, \eta) \cdot \eta\right\rangle
$$

According to (3) we directly obtain that

(4) $t \in \mathbf{N}_{1}$ implies $\tau^{n}\left(t, \eta_{i}\right) \in \mathbf{N}_{1}$ for $n \in \mathbf{N}$ and $i=1,2$.

Since $j=S_{n}\left(\xi_{2}\right) \in \mathbf{N}$ for all $n \geqq n_{0}$ according to (1), there exist exactly $j$ elements $t_{i} \in \mathbf{N}_{1}, i=1, \cdots, j$ with

$$
n_{0}<t_{1}<t_{2}<\cdots<t_{j} \leqq\left\langle n_{0} \cdot \eta_{2}\right\rangle .
$$

Since $\eta_{2}>1,(5)$ implies

$$
\tau^{n}\left(n_{0}, \eta_{2}\right)<\tau^{n}\left(t_{1}, \eta_{2}\right)<\cdots<\tau^{n}\left(t_{j}, \eta_{2}\right) \leqq \tau^{n+1}\left(n_{0}, \eta_{2}\right)
$$

for all $n \in \mathbf{N}$. Now we obtain from relations (1), (4), (5) and (6) that

$$
\mathbf{N}_{1}=\left\{\tau^{n}\left(t_{i}, \eta_{2}\right): i=1, \cdots, j, n \in \mathbf{N} \cup\{0\}\right\} .
$$

As by (4) $\tau^{n}\left(t_{1}, \eta_{1}\right) \in \mathbf{N}_{1}$, according to (7) for each $n \in \mathbf{N}$ there exist $k(n) \in \mathbf{N}, i(n) \in\{1, \cdots, j\}$ with

$$
\tau^{n}\left(t_{1}, \eta_{1}\right)=\tau^{k(n)}\left(t_{i(n)}, \eta_{2}\right)
$$

By induction it is easily proved that

$$
\left|\tau^{n}(t, \eta)-t \eta^{n}\right| \leqq 1+\eta+\cdots+\eta^{n-1}=\left(\eta^{n}-1\right) /(\eta-1)
$$

for $t \in \mathbf{N}$ and $n>1$.

Since $t_{i}<\eta_{2} t_{1}$ for $i=1, \cdots, j$ (see (5)) there exist $x_{i} \in[0,1]$ with 
$t_{i}=t_{1} \eta_{2}^{x_{i}}$. Then $x_{1}=0<x_{2}<\cdots<x_{j}<1=: x_{j+1}$. Hence there exists $l \in\{1, \cdots, j\}$ with

$$
x_{l+1}-x_{l} \geqq \frac{1}{j}
$$

Let us now assume that $z$ is irrational. According to ([2], p. 69) there exists an element $m \in \mathbf{N}$ with

$$
x_{l}+\frac{1}{3 j}<m z-[m z]<x_{l}+\frac{2}{3 j} \text {. }
$$

Since $\eta_{1}=\eta_{2}^{z}$ we obtain from (8) and (9) that

$$
\left|t_{1} \eta_{2}^{m z}-t_{i(m)} \eta_{2}^{k(m)}\right| \leqq \frac{1}{\eta_{1}-1} \eta_{2}^{m z}+\frac{1}{\eta_{2}-1} \eta_{2}^{k(m)}
$$

and hence

$$
\left|t_{1} \eta_{2}^{m z}-t_{i(m)} \eta_{2}^{k(m)}\right| \leqq \frac{2}{\eta_{2}-1} \eta_{2}^{\max (m z, k(m))}
$$

Now we distinguish four cases

(i) If $m z<k(m)$ then $m z-k(m) \leqq-1 / 3 j$ according to (10) and (11). Hence we obtain from (5) and (2) that

$$
\left|t_{1} \eta_{2}^{m z-k(m)}-t_{i(m)}\right| \geqq t_{1}-t_{1} \eta_{2}^{m z-k(m)} \geqq \mid t_{1}\left(1-\eta_{2}^{-1 / 3)}\right)>\frac{2}{\eta_{2}-1}
$$

which contradicts (12).

In the following three cases we assume that $m z>k(m)$.

(ii) Let $i(m) \leqq l$ : As $m z-k(m) \geqq x_{i}+1 / 3 j$ by (11) we obtain from (5) and (2) that

$$
\left|t_{1}-t_{i(m)} \eta_{2}^{k(m)-m z}\right| \geqq t_{1}-t_{1} \eta_{2}^{x_{i(m)}+k(m)-m z} \geqq t_{1}\left(1-\eta_{2}^{-1 / 3}\right)>\frac{2}{\eta_{2}-1}
$$

which contradicts (12).

(iii) Let $i(m)>l$ and $[m z]=k(m)$ : Then $m z-k(m) \leqq x_{l+1}-1 / 3 j$ by (10) and (11), and we obtain from (5) and (2) that

$$
\left|t_{1}-t_{i(m)} \eta_{2}^{k(m)-m z}\right| \geqq t_{l+1} \eta_{2}^{-\left(x_{l+1}-1 / 3 j\right)}-t_{1}=t_{1}\left(\eta_{2}^{1 / 3 j}-1\right)>\frac{2}{\eta_{2}-1}
$$

which contradicts (12).

(iv) If $i(m)>l$ and $[m z]>k(m)$, then $m z-k(m) \geqq 1+1 / 3 j$ by (11), and we obtain from (5) and (2) 


$$
\left|t_{1}-t_{i(m)} \eta_{2}^{k(m)-m z}\right| \geqq t_{1}-t_{j} \eta_{2}^{-(1+1 / 3 j)} \geqq t_{1}-t_{1} \eta_{2}^{-1 / 3 j}=t_{1}\left(1-\eta_{2}^{-1 / 3}\right)>\frac{2}{\eta_{2}-1}
$$

which contradicts (12).

Thus we have shown that the assumption of $z$ being irrational leads to a contradiction.

If $r, s \in \mathbf{N}$ denote by $(r, s)$ the greatest common divisor of $r$ and $s$.

The following remark shows that for two rational numbers condition $\left({ }^{*}\right)$ of Theorem 3 is nearly always fulfilled.

REMARK 4. If $\xi_{1}, \xi_{2} \in(0,1)$ are rational numbers and $\xi_{1}^{r}=\xi_{2}^{s}$ for $r, s \in \mathbf{N}$ with $(r, s)=1$ then there exist $t, u \in \mathbf{N}$ such that $\xi_{1}=(t / u)^{s}$ and $\xi_{2}=(t / u)^{r}$.

Proof. Let w.l.g. $\xi_{i}=l_{i} / m_{i}$ where $l_{i}, m_{i} \in \mathbf{N}$ and $\left(l_{i}, m_{i}\right)=1$ for $i=1$, 2. If $\xi_{1}^{r}=\xi_{2}^{s}$ i.e. $l_{1}^{r} m_{2}^{s}=l_{2}^{s} m_{1}^{r}$, then $l_{1}^{r}=l_{2}^{s}$ and $m_{1}^{r}=m_{2}^{s}$.

We may choose $r$ and $s$ such that $(r, s)=1$. Then by representation of $l_{i}, m_{i}$ as a product of prime numbers we obtain $t, u \in \mathbf{N}$ with

$$
t^{s}=l_{1}, \quad t^{r}=l_{2} \quad \text { and } \quad u^{s}=m_{1}, \quad u^{r}=m_{2} .
$$

According to Theorem 3 Cases I and II can occur. According to Example 2 of [4] it is not possible to exclude Case II. Even if $S_{n}(\xi, A)$, $n \in \mathbf{N}$, converges for each rational number $\xi \in(0,1)$ the sequence $a_{n}, n \in \mathbf{N}$, need not converge to zero.

We remark that the following questions remain unsolved:

(1) If $\xi_{1}$ and $\xi_{2}$ are two different irrational numbers, does the convergence of $S_{n}\left(\xi_{i}, A\right), n \in \mathbf{N}$, (for $i=1,2$ ) imply that $a_{n}, n \in \mathbf{N}$, converges to zero?

(2) Give an exact characterization of those pairs of rational numbers $\xi_{1}, \xi_{2}$ for which only Case I or II is possible; is for instance the condition $\left({ }^{*}\right)$ of Theorem 3 such an exact characterization?

\section{REFERENCES}

1. R. Bojanic and E. Seneta, A unified theory of regularly varying sequences, Mathematische Zeitschrift, to appear.

2. P. R. Halmos, Measure Theory, Van Nostrand Company, Princeton - New Jersey - London (1950).

3. R. Higgins, A note on a problem in the theory of sequences, Elemente der Mathematik, (1974), 37-39.

4. D. Landers and L. Rogge, On three problems for sequences, Manuscripta Mathematica, 17 (1975), 221-226.

Received February 11, 1976.

UNIVERSITÄT KONSTANZ

Fachbereich Wirtschaftswissenschaften Statistik 



\section{PACIFIC JOURNAL OF MATHEMATICS}

\section{EDITORS}

RICHARD ARENS (Managing Editor)

University of California

Los Angeles, California 90024

\author{
R. A. Beaumont \\ University of Washington \\ Seattle, Washington 98105
}

\section{J. DugunduI}

Department of Mathematics University of Southern California Los Angeles, California 90007

D. Gilbarg and J. Milgram

Stanford University

Stanford, California 94305

\section{ASSOCIATE EDITORS}

E. F. BECKENBACH
B. H. NeumanN

F. Wolp
K. YoshidA

\section{SUPPORTING INSTITUTIONS}

UNIVERSITY OF BRITISH COLUMBIA

CALIFORNIA INSTITUTE OF TECHNOLOGY

UNIVERSITY OF CALIFORNIA

MONTANA STATE UNIVERSITY

UNIVERSITY OF NEVADA

NEW MEXICO STATE UNIVERSITY

OREGON STATE UNIVERSITY

UNIVERSITY OF OREGON

OSAKA UNIVERSITY

\author{
UNIVERSITY OF SOUTHERN CALIFORNIA \\ STANFORD UNIVERSITY \\ UNIVERSITY OF HAWAII \\ UNIVERSITY OF TOKYO \\ UNIVERSITY OF UTAH \\ WASHINGTON STATE UNIVERSITY \\ UNIVERSITY OF WASHINGTON \\ AMERICAN MATHEMATICAL SOCIETY
}

The Supporting Institutions listed above contribute to the cost of publication of this Journal, but they are not owners or publishers and have no responsibility for its contents or policies.

Mathematical papers intended for publication in the Pacific Journal of Mathematics should be in typed form or offset-reproduced (not dittoed). double spaced with large margins. Underline Greek letters in red, German in green, and script in blue. The first paragraph or two must be capable of being used separately as a synopsis of the entire paper. Items of the biblography should not be cited there unless absolutely necessary, in which case they must be identified by author and Journal, rather than by item number. Manuscripts, in duplicate, may be sent to any one of the four editors. Please classify according to the scheme of Math. Reviews, Index to Vol. 39. All other communications should be addressed to the managing editor, or Elaine Barth, University of California, Los Angeles, California, 90024.

100 reprints are provided free for each article, only if page charges have been substantially paid. Additional copies may be obtained at cost in multiples of 50 .

The Pacific Journal of Mathematics is issued monthly as of January 1966. Regular subscription rate: $\$ 72.00$ a year (6 Vols., 12 issues). Special rate: $\$ 36.00$ a year to individual members of supporting institutions.

Subscriptions, orders for back numbers, and changes of address should be sent to Pacific Journal of Mathematics, 103 Highland Boulevard, Berkeley, California, 94708.

PUBLISHED BY PACIFIC JOURNAL OF MATHEMATICS, A NON-PROFIT CORPORATION Printed at Jerusalem Academic Press, POB 2390, Jerusalem, Israel.

Copyright (C) 1976 Pacific Journal of Mathematics All Rights Reserved 


\section{Pacific Journal of Mathematics}

\section{Vol. 64, No. $2 \quad$ June, 1976}

Richard Fairbanks Arnold and A. P. Morse, Plus and times............. 297

Edwin Ogilvie Buchman and F. A. Valentine, External visibility ......... 333

R. A. Czerwinski, Bonded quadratic division algebras.............. 341

William Richard Emerson, Averaging strongly subadditive set functions in unimodular amenable groups. II .........................

Lynn Harry Erbe, Existence of oscillatory solutions and asymptotic behavior for a class of third order linear differential equations ............. 369

Kenneth R. Goodearl, Power-cancellation of groups and modules........ 387

J. C. Hankins and Roy Martin Rakestraw, The extremal structure of locally compact convex sets ...................................

Burrell Washington Helton, The solution of a Stieltjes-Volterra integral

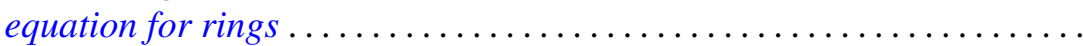

Frank Kwang-Ming Hwang and Shen Lin, Construction of 2-balanced

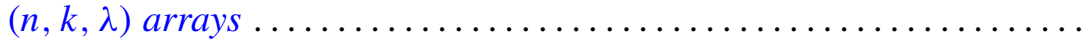

Wei-Eihn Kuan, Some results on normality of a graded ring ... 455

Dieter Landers and Lothar Rogge, Relations between convergence of series and convergence of sequences ......................... 465

Lawrence Louis Larmore and Robert David Rigdon, Enumerating immersions and embeddings of projective spaces ................

Douglas C. McMahon, On the role of an abelian phase group in relativized problems in topological dynamics..................

Robert Wilmer Miller, Finitely generated projective modules and TTF classes...

Yashaswini Deval Mittal, A class of isotropic covariance functions ...

Anthony G. Mucci, Another martingale convergence theorem ...

Joan Kathryn Plastiras, Quasitriangular operator algebras ...

John Robert Quine, Jr., The geometry of $p\left(S^{1}\right) \ldots \ldots \ldots$. 